as places where motorists unquestionably belonged."

My only reservations about this excellent book are its over-reliance on sociological jargon and that there is not enough discussion of the economic benefits that made the car so successful. In most advanced economies, motor vehicles account for more than $70 \%$ of passenger and freight mobility. The increase in mobility has reduced the monopoly power of city-centre landlords, allowing better and cheaper housing in the suburbs. At the same time, the monopoly power of central business has been reduced by the competition offered by out-of-town retailers. These benefits have improved economic efficiency, but at a considerable environmental cost. Maybe the author should consider writing a sequel about the 'dusk of the motor age' as strong environmental, economic, social and political pressures increasingly threaten motorists' freedom.

Marcial Echenique is professor of land use and transport studies at the Department of Architecture, University of Cambridge, 1-5 Scroope Terrace, Cambridge CB2 1PX, UK. He and Andrew Saint edited Cities for the New Millennium.

\title{
In Retrospect: The chromosome trail
}

\section{A new translation of Theodor Boveri's 1914 monograph brings the early origins of contemporary cancer research to a wider readership, contends Robert A. Weinberg.}

Concerning the Origin of Malignant
Tumours
by Theodor Boveri. Translated and
annotated by Henry Harris
Cold Spring Harbor Laboratory Press: 2008.
82 pp.

Theodor Boveri (1862-1915) was a towering figure in cell biology and cancer research during the early twentieth century. Trained as a zoologist, he probed the workings of the nucleus and cytoplasm of cells by perturbing them in invertebrate embryos. He was particularly interested in the contributions of chromosomes to cell behaviour. His speculative monograph on the connection between chromosomal anomalies and their role in cancer, published in German in 1914, sealed his scientific reputation.

This monograph, an important source of the origins of contemporary cancer research, has now been translated into English for the second time by Henry Harris, a pioneer in the discovery of tumour-suppressor genes. Boveri's widow and co-worker, Marcella O'Grady Boveri, published the first translation in 1929. Realizing that German biomedical research had begun to lose its dominance worldwide and that German was no longer the sole language of science, she undertook to bring her husband's work to the attention of the non-German-speaking scientific world. Harris's translation presents Boveri's ideas in more contemporary English and is far more accessible. Frequent explanatory footnotes set the arguments in the context of recent findings and, on occasion, in light of twenty-first-century cancer research.

Boveri is remembered for the seminal idea, laid out in Concerning the Origin of Malignant Tumours, that chromosomes are the seats of cell heredity, and that the atypical chromosomes often seen in cancer cells are the basis of these cells' aberrant behaviour. In truth, much of the credit for this prescient suggestion should go to the pathologist David von Hansemann, who, beginning in 1890, published a series of papers on the subject. Von Hansemann noted the tight association between abnormal numbers of chromosomes (aneuploidy) and malignant tissues (neoplasias), but he did not conclude that one invariably causes the other. Boveri notes von Hansemann's contribution in passing and presents evidence for just that conclusion.

To this day, von Hansemann's work remains relatively unknown. He lacked a doting widow to translate his own body of work. And Boveri was a more dominating personality — an otherwise uncritical student described him as a "vehement, inflexible and relentless assailant". Boveri's eclipsing of von Hansemann is reminiscent of how Rudolf Virchow, widely credited with the dictum that all cells arise from the division of pre-existing cells, lifted the idea from the less well-connected Robert Remak, a neurologist who repeatedly reported this finding in the years before Virchow's famous 1858 paper.

Boveri manipulated sea-urchin eggs and embryos. He stripped eggs of their nuclei or fertilized them with multiple sperm. By so doing, he produced evidence for the theory, already in wide circulation, that the determinants of heredity lie in the nucleus, not in the cytoplasm, and that faulty cell division is responsible for the presence of abnormal numbers of chromosomes. From his later experiments, he deduced that each chromosome within a single nucleus must carry a distinct type of heritable information and that proper embryonic development depends on the inheritance of the correct complement of chromosomes.

Boveri seems to have been unaware of the dramatic revolution in genetics that followed the rediscovery in 1900 of Gregor Mendel's all-but-forgotten research into inherited traits. Soon after the rediscovery, several scientists noted the striking parallels between Mendel's genetic determinants and the behaviour of chromosomes - by then known to be present in pairs in ordinary cells, and only singly in sperm and eggs. None of these insights features in the 1914 monograph.

He also studied the two poles that appear at the opposite ends of a cell that is about to divide. These poles anchor and organize the spindle fibres that pull apart two sets of chromosomes during cell division, ensuring each daughter cell receives one complete set. Boveri's focus on the spindles that arise in cells with four poles, rather than the usual two, as the main source of abnormal chromosome numbers now seems simplistic. But it was a good start given the limited experimental tools at his disposal.

What makes Boveri's writing worth reading almost a century later is his ability to distil complex information, including the ideas and observations of others, into brilliant, incisive syntheses. For those biologists among us who are interested in how we got to where we are, this book makes fascinating reading, even if it does not lay down an accurate trail of previous discoveries. Cancer research over the past century has involved a succession of blind alleys and detours, mountains of largely uninterpretable observational data and the occasional brilliant leap forward. This book takes us back to the humble beginnings of this now thriving field.

Robert A. Weinberg is a member of the Whitehead Institute for Biomedical Research and professor of biology, Massachusetts Institute of Technology, 9 Cambridge Center, Cambridge, Massachusetts 02142, USA. He is author of The Biology of Cancer. 